\title{
Evaluación en el agua para consumo humano de subproductos de cloración y su relación como inductores de mutagénesis (mutaciones celulares)
}

\section{Evaluation of drinking water chlorination by-products and their relationship to induce mutagenesis (cell mutations)}

Virginia Montero-Campos'

Rodrigo Chinchilla-Montero ${ }^{2}$

Ricardo Coy-Herrera²

Ana Laura Agüero-Hernández ${ }^{2}$

Joaquín Jiménez-Antillón ${ }^{3}$

Montero-Campos, V; Chinchilla-Montero, R; CoyHerrera, R; Agüero-Hernández, A; Jiménez-Antillón, J. Evaluación en el agua para consumo humano de subproductos de cloración y su relación como inductores de mutagénesis (mutaciones celulares). Tecnología en Marcha. Número Especial. Pág 22-29.

I Escuela de Química, Instituto Tecnológico de Costa Rica. Centro de Investigación y de Servicios Químicos y Microbiológicos (CEQIATEC), Instituto Tecnológico de Costa Rica. Correo electrónico: vmontero@itcr.ac.cr.Tel. 2550 9137.

2 Centro de Investigación y de Servicios Químicos y Microbiológicos (CEQIATEC), Instituto Tecnológico de Costa Rica.

3 Centro de Investigación en Protección Ambiental (CIPA), Instituto Tecnológico de Costa Rica. 


\section{Virginia Montero Campos}

Virginia Montero Campos es casada con dos hijos, y la hija menor de seis hermanos. Oriunda de Guadalupe de Goicoechea es de los "Campos de Guadalupe" como solían llamarnos, según comenta, pues proviene de una de las familias pilares de ese cantón, de hecho los primos seguimos manteniendo las propiedades de la familia en el centro de Guadalupe, según agrega.

Microbióloga de profesión y de corazón, porque como dice "si tuviera que volver a empezar escogería la misma carrera, yo creo que no cambiaría nada de lo hecho".

Sus padres fallecieron a tempranas edades, su padre cuando cursaba la universidad y su madre poco tiempo antes de entrar al TEC. Al fallecer su madre de cáncer gástrico (una de las patologías que aqueja más a los costarricenses a nivel mundial) y tener base para relacionarla con agua de consumo humano en Costa Rica, hace que este fuera su tema de tesis doctoral por el cual recibió una mención honorifica "SUMMA CUM LAUDE", "esto se ha se constituido en una de las satisfacciones más grandes que he recibido".

Después de Dios, familia y trabajo, esto lo ha hecho como un lema en su vida personal por cuanto según comneta no es raro que mucho de "mi tiempo libre", lo siga dedicando a actividades académicas o sea fines de semana, mis hijos dicen que si tuvieran hoy en la escuela que dibujar a su mamá la dibujarían en una computadora.

Parte de este fenómeno anterior es su deseo de ayudar a la gente, "entonces me piden muchas cosas y no puedo decir que no", dice que siente que si puede ayudar a alguien, lo hace; por lo que "crea fama y échate a dormir se aplica mucho a mi vida", pues no solo en el plano personal esto se aplica, sino que como comenta, he recibido solicitudes de otros países para cooperar con cursos, investigaciones, revisiones de trabajos, tesis, asesorías en mis campos de competencia", además como adiciona: "una vez recibí en mi celular una llamada desde España para que participara en una consultoría a Republica Dominicana".

Desde el punto de vista académico tiene dos pasiones: la docencia y la investigación, "me encanta dar clases y como soy una enamorada de la micro- biología, pues como que le imprimo ese gusto a los estudiantes, y siento mucha retroalimentación positiva de parte de ellos", en este sentido me mantengo muy ocupada dándole cursos a dos Escuelas Química y Biología, y me siento bien así "creo que es parte de lo eléctrica que soy".

En la investigación según comenta uno de los beneficios y de sus aportes al área, es la ejecución de proyectos en agua potable, " siento que al dedicarme a investigar en uno de los ejes más sensibles del desarrollo sostenible, estoy ayudando a muchas personas a la vez" y para terminar de enredar la situación " me gusta investigar cosas raras", temas muy poco conocidos o no determinados en el ámbito nacional, porque como manifiesta "para que investigar de lo qué muchos saben, ¿cuál sería entonces el aporte al nuevo conocimiento científico?".

Al ser el agua potable un tema de investigación obligado, casi todos sus proyectos han sido en esta matriz, aunado, según comenta, a una de las áreas fascinantes para mí: la toxicología ambiental, en esta misma línea esos resultados de investigaciones han calado en instituciones nacionales de esta competencia; no obstante me he preocupado no solo por medir o determinar un problema sino contribuir con la solución, me parece que es el insumo más importante que deberíamos de aportarle al país, soluciones tecnológicas a problemas de difícil abordaje, así ha investigado de Helicobacter pylori, nitratos, productos tóxicos que se generan en el proceso de cloración y arsénico.

Pero según manifiesta no podría llevar a cabo tantas cosas sin la ayuda de otras personas, primero mi familia, que comprende y apoya lo que hago, especialmente de mi esposo, pues al ser microbiólogo esto también nos permite intercambiar temas de conversación, mis hijos que me han apoyado siendo autosuficientes y responsables pues yo también los he apoyado en sus cosas siempre, mi compañeros profesionales investigadores y mis estudiantes "que yo creo que también se les contagia la electricidad".

Finalmente casi todos los días le doy gracias a Dios por haberme dado la oportunidad de colocarme en este TEC, al que siempre he considerado una tierra tan fértil que prácticamente cualquier semilla que siembre irremediablemente germinará. 


\section{Palabras clave}

Trihalometanos; subproductos de desinfección; cloración; agua potable.

\section{Resumen}

En el proceso de cloración del agua se produce una serie de reacciones químicas entre el cloro utilizado en la desinfección y la materia orgánica presente en el agua. La naturaleza y la concentración de los compuestos formados son dependientes de variables físicoquímicas de la materia orgánica del suelo, las cuales reaccionan con el cloro agregado originándose productos que son compuestos de diferente toxicidad, entre ellos los mutagénicos y carcinogénicos; a todos ellos en conjunto se les conoce como productos secundarios de cloración (SPD, por sus siglas en inglés), en los que se incluyen los compuestos llamados trihalometanos (THM). Se investigó la presencia de este tipo de subproductos en aguas costarricenses por medio de la técnica de microextracción en fase sólida (HEADSPACE / SPME Solid Phase Microextraction / GS-MS), utilizando un Cromatógrafo de Gases Varian 450 acoplado a un Espectrómetro de Masas.

Se analizaron en total 39 muestras, provenientes de fuentes de agua subterránea (nacientes) administradas por la Municipalidad del Cantón Central de Cartago y agua de origen superficial (plantas de tratamiento completo) dispensada por los sistemas de tratamiento del AyA/Cantón Central de Cartago y los Sistemas de Tratamiento del AyA de Moravia, Guadalupe y Pavas, con un total de I 56 subproductos determinados y cuantificados, correspondiendo estos a cloroformo, bromodiclorometano, dibromoclorometano y tribromoclorometano.

En las muestras de agua de los sistemas de tratamiento completo se encontró que de 80 subproductos analizados, 12 superaron el máximo permitido de acuerdo con el Reglamento Nacional de Calidad de Agua para consumo humano, mientras que de los acueductos abastecidos por medio de aguas subterráneas administrados por la Municipalidad de Cartago, de 76 subproductos analizados solo uno superó el valor máximo permitido.

\section{Key words}

Trihalomethanes; byproducts of disinfection; chlorination; drinking water.

\section{Abstract}

In the chlorination process produces a series of chemical reactions between the chlorine used in the disinfection and the organic matter present in the water to be treated. The nature and concentration of the compounds formed, are dependent physicochemical variables of soil organic matter, which react with chlorine added products originating from different compounds, are toxic, mutagenic and carcinogenic including, all together are known as chlorination byproducts (acronym SPD), which include compounds called trihalomethanes (THM's). It was investigated the presence of these types of products in costa rican waters by the technique of solid phase microextraction (HEADSPACE / SPME Solid Phase Microextraction / GS-MS), using a Varian 450 Gas Chromatograph Mass Spectrometer coupled. It was analyzed 39 samples of water from local groundwater sources and surface water sources (full treatment plants) in users homes dispensed by treatment systems / Central Canton of Cartago and Costa Rican Water and Sewer Institute Plants of Moravia, Guadalupe and Pavas, with a total of 156 products identified and quantified corresponding these to: chloroform, bromodichloromethane, and tribromochloromethane dibromochloromethane. In water samples complete treatment systems found that 80 products was analyzed, 12 of these exceeded the maximum allowed according to National Regulations for Water Quality human consumption, while the aqueducts supplied by groundwater administered by the Municipality of Cartago, 76 products was analyzed, only one of them exceeded the maximum allowed. 


\section{Introducción}

A pesar de que la desinfección del agua con cloro para consumo humano ha representado en el mundo una disminución de la incidencia de enfermedades infecciosas, se han encontrado sustancias o subproductos de la desinfección que presentan posibles efectos genotóxicos para la salud de las personas (EPA, 2000).

En el proceso de cloración del agua se produce una serie de reacciones químicas entre el cloro utilizado en la desinfección y la materia orgánica presente en el agua. La naturaleza y la concentración de los compuestos formados son dependientes de variables físicoquímicas de la materia orgánica del suelo, las cuales reaccionan originándose productos que son compuestos de diferente toxicidad, entre ellos mutagénicos y carcinogénicos; a todos en conjunto se les conoce como productos secundarios de cloración (SPD, por sus siglas en inglés), que incluyen compuestos llamados trihalometanos (THM) y ácidos haloacéticos (HAA) (Calderón, 2002).

Esto es preocupante, ya que los mutágenos presentes en el agua de consumo humano llegan continuamente a la población durante largo tiempo, lo que puede ocasionar enfermedades tales como tumores benignos o malignos (cáncer) y otras patologías relacionadas con el sistema inmune, además de efectos adversos en mujeres embarazadas (Aggazzotti et al, 2004, Dodds et al, 2004). Varios estudios epidemiológicos han demostrado que el consumo de agua clorada sin el adecuado manejo y tratamiento está asociado a un incremento en el riesgo de cáncer gástrico, de vejiga y de recto (Nieuwenhuijsen et al., 2009).

Los THM originados durante este proceso de cloración incluyen cloroformo $\left(\mathrm{CHCl}_{3}\right)$, bromodiclorometano, clorodibromometano, bromoformo y tetracloruro de carbono, entre otros compuestos volátiles. Se ha descrito que el cloroformo en altas dosis es cancerígeno y que los otros THM son mutagénicos (Cloroformo, 2007).

En general, el Reglamento de Calidad de Agua para consumo humano en Costa Rica contempla la determinación y el análisis de 14 compuestos diferentes. A la fecha, en el país no se ha llevado a cabo una investigación similar ni se ha determinado este tipo de compuestos en el agua de consumo humano por parte de análisis de laboratorios nacionales.
En varios trabajos se ha encontrado que uno de los principales mutágenos formados en el agua clorada es el 3-cloro-4-diclorometil-5 hidroxi 2-H-furanona, un mutágeno directo que puede producir entre 4000 y 13000 mutaciones en pruebas in vitro de mutagénesis inducida, además de producir cáncer de tiroides, hígado y adenomas foliculares en bronquios, pulmones y páncreas en ratas (Villanueva et al., 2007).

La preocupación por la exposición a agentes mutagénicos en nuestro medio ambiente se basa fundamentalmente en la premisa de que los compuestos químicos que dañan el ADN de las células germinales pueden incrementar la incidencia de mutaciones heredables y alteraciones genéticas, y los compuestos químicos que dañan el ADN de las células pueden influir en el inicio del cáncer (Villanueva et al., 2007). Muchos autores han puesto de manifiesto una alta correlación cualitativa en la capacidad de estos productos químicos para inducir mutaciones en bacterias y causar cáncer en animales de experimentación.

Durante el proceso de potabilización y distribución del agua ocurre una serie de reacciones químicas entre los agentes de desinfección y compuestos orgánicos presentes en el agua, que se conocen también como ácidos húmicos (cuyo nombre deriva de humus) y ácidos fúlvicos, los cuales se encuentran tanto en el agua superficial como en la profunda y son el producto de la degradación de sustancias vegetales (maderas, tallos, raíces, etc.) como la lignina, que le confiere color al agua (Berdonces et al., 2008).

Estos compuestos activos, al entrar en contacto con los derivados del cloro, propician la formación de subproductos de la desinfección SPD o DBP (siglas en inglés de disinfectant by-product), muchos de los cuales se han identificado como potencialmente perjudiciales para la salud humana (Ríos, 2004). Entre estos compuestos están los trihalometanos (THM), ácidos haloacéticos (HAA), además de los haloacetonitrilos (HAN), haloaldehídos y haloacetonas.

Los trihalometanos conforman el grupo de subproductos más difundido e identificado en las reglamentaciones de los distintos países. Se forman a partir de la sustitución de 3 átomos de hidrógeno del metano $\left(\mathrm{CH}_{4}\right)$ por átomos de un halógeno (cloro o bromo y eventualmente yodo) (Ríos, 2004). 


$$
\text { Cloro }+\mathrm{NOM}+\text { Bromo }=\mathrm{THM}
$$

Los trihalometanos se subdividen en triclorometanos (cloroformo, $\mathrm{CHCl}_{3}$ ), bromodiclorometano (BDCM, $\left.\mathrm{CHBrCl}_{2}\right)$, clorodibromometano $\left(\mathrm{CHBr}_{2} \mathrm{Cl}\right)$ y tribromometano $\left(\mathrm{CHBr}_{3}\right)$. El cloroformo es el trihalometano más común y el principal subproducto de la desinfección presente en el agua de consumo clorada.

En algunas investigaciones realizadas se ha considerado que la naturaleza y la concentración de los DBP son dependientes de variables como el tipo y la concentración del desinfectante utilizado, la cantidad de materia orgánica presente en el agua natural, temperatura, fuerza iónica, cantidad de cloro residual, concentración de bromo, tiempo de contacto con el agente desinfectante y el pH. (Vuolo et al., 20I3, Sánchez et al., 2008); mientras que Ochoa menciona que la formación de subproductos se ve favorecida con el aumento de la dosis de cloro, ya que está comprobado que los contenidos de THM a la salida de las estaciones de tratamiento se incrementan posteriormente en muchos casos, ya en la red, debido principalmente al mayor tiempo de contacto con la materia orgánica que sale de la estación y con sustancias orgánicas que forman biofilmes en la red (Ochoa, 2004).

En un estudio en Barcelona también se relacionó la fuerza iónica, ya que se obtuvieron valores de THM relativamente bajos en muestras de agua del río Ter, que se catalogó como de baja conductividad, predominando el cloroformo y el bromodiclorometano, mientras que en las del río Llobregat, que se encuentra en una zona rica en minas de potasa que aporta sales de potasio condicionando su alta conductividad, presentó valores de THM más elevados, que superan los $100 \mu \mathrm{g} / \mathrm{L}$, predominando el bromoformo y el dibromoclorometano (Calderón et al., 2002).

Desde la aparición del "Test de Ames", en 1975, se ha estudiado la actividad mutagénica de muestras de cualquier líquido. Hoy el test UMUC EASY AQ, variación del test, es capaz de responder a sustancias químicas con diversos mecanismos mutagénicos, incluidos eventos de entrecruzamiento con y sin activación metabólica, tales como este tipo de subproductos.

En el caso de nuestro país, la desinfección del agua se encuentra normada por el Reglamento de calidad del agua potable, Decreto No 32327-S2, en cuyo Artículo 12 se señala la utilización de la desinfección: como parte de una serie de operaciones y procesos de tratamiento unitario en una planta. En su forma más simple se aplica como único tratamiento de aguas naturales de excelente calidad (aguas subterráneas o de manantial) para garantizar la ausencia de indicadores de contaminación fecal entre el punto de aplicación y el punto de entrega al usuario. La desinfección deberá aplicarse además para mantener un nivel residual máximo 0,6 mg/L, según lo indicado en el Artículo 13, que garantice la calidad del agua para que esté libre de contaminaciones eventuales a través de todo el sistema de distribución (República de Costa Rica, 2005).

\section{Metodología}

En la técnica empleada para la determinación de trihalometanos se utilizó el Estándar de Trihalometanos EPA 55IA Halogenated Volatiles Mix, de Supelco, compuesto por 10 sustancias: trihalometanos (bromoformo, cloroformo, bromodiclorometano y dibromoclorometano), trihaloetanos ( I,2 dibromoetano, I, I, I tricloroetano, trihaloeteno, tricloroetileno), trihalopropanos (I,2 dibromo 3, cloropropano), tetrahalometano (tetracloruro de carbono).

Se utilizó la técnica de Microextracción en fase sólida (HEADSPACE / SPME Solid Phase Microextraction / GS-MS), con un Cromatógrafo de Gases Varian 450 acoplado a un Espectrómetro de Masas. Tanto las muestras de agua potable como los estándares de compuestos halogenados volátiles se procesaron en viales de vidrio ámbar de 2 oz con septum de Politetrafluoroetileno (PTFE). El volumen de extracción fue de $30 \mathrm{~mL}$ con una profundidad de fibra de 3,2 cm expuesta a la cabeza de aire (HS); se utilizaron fibras de Carboxen/Polidimetilsiloxane Stable Flex de $85 \mu \mathrm{m}$ light Blue (85 $\mu \mathrm{m}$ CAR/PDMS) de Supelco; la temperatura de extracción fue de $45^{\circ}$ C con una agitación de 300 RPM, el tiempo de absorción fue de 30 minutos mientras que el de desorción en el inyector fue de 4 minutos; posteriormente a la inyección las fibras se acondicionaron por 25 minutos en contacto con una corriente de Helio a $270^{\circ} \mathrm{C}$ para eliminar residuos remanentes y su posterior reutilización.

Se llevó a cabo también un análisis de carbono orgánico total (TOC), por el método Standard Methods $5310 \mathrm{C}$ con persulfato de sodio-oxidación ultravioleta, en un TELEDYNETEKMAR TOC Fusion. 


\section{Resultados y discusión}

Se evaluaron los parámetros de veracidad, repetibilidad, reproducibilidad, incertidumbre y los límites de cuantificación y detección, según los parámetros de la EURACHEM y la INTE/ISO- I 7025:2005.

Se analizaron en total 39 muestras, provenientes de fuentes de agua subterránea (nacientes) administradas por la Municipalidad del Cantón Central de Cartago y agua de origen superficial (plantas de tratamiento completo) dispensada por los sistemas de tratamiento del AyA/Cantón Central de Cartago y los Sistemas de Tratamiento del AyA de Moravia, Guadalupe y Pavas, (muestras recolectadas en casas de usuarios), con un total de 156 subproductos determinados y cuantificados, correspondiendo estos a cloroformo, bromodiclorometano, dibromoclorometano y tribromoclorometano.

En las muestras de agua de los sistemas de tratamiento completo se encontró que de 80 subproductos analizados, 12 superaron el máximo admisible según el Reglamento Nacional de Calidad de Agua para consumo humano, mientras que de los acueductos abastecidos por aguas subterráneas administrados por la Municipalidad de Cartago, de 76 subproductos analizados solo uno superó el valor máximo permitido.

En el cuadro I se presentan los valores de las muestras encontradas positivas por tipo de sistema de tratamiento.

Con respecto a los valores de carbono orgánico total, se obtuvo que las aguas de naciente contenían valores de 0,30 mg/L a I,26 mg/L y el agua superficial un valor $2,3 \mathrm{mg} / \mathrm{L}$ determinado en verano, sin embargo, estos valores podrían estar aumentados en el invierno. De acuerdo con lo establecido por la Agencia de Protección Ambiental de Estados Unidos (EPA), el agua que va a ser clorada no debería superar valores promedio anuales de 2,0 mg/L de carbono orgánico total; la práctica ausencia de subproductos encontrados en las muestras cloradas en sistemas de agua subterránea descarta la relación de influencia del tipo de suelo en la formación de tipos específicos de subproductos.

Se pudo determinar, tal y como lo muestra la literatura, que la formación de subproductos se ve favorecida con el aumento en la dosis de cloro (no con el cloro residual) y con el aumento del tiempo de contacto agua-cloro, ya que está comprobado que los contenidos de THM a la salida de las plantas de tratamiento se incrementan posteriormente, en muchos casos en la red, debido principalmente al mayor tiempo de contacto con la materia orgánica y con sustancias orgánicas que forman biofilmes en la red. Cuando las muestras presentaban subproductos en altas concentraciones, estos tendían a aumentar con el tiempo, incluso entre ensayos de muestras duplicadas tomadas en el mismo momento en la misma fuente.

Lo anterior toma relevancia en aguas de plantas de tratamiento completo que permanecen almacenadas en tanques cerrados, pues dichos subproductos, cuando están en alta cantidad, tienden a aumentar con el tiempo sin poderse determinar cuánto.

En cuanto a la toxicidad de los subproductos encontrados se tiene que, con respecto al bromodiclorometano, los efectos de exposición prolongada o repetida a dicho compuesto pueden afectar el

Cuadro I.Valores de las muestras encontradas

\begin{tabular}{|c|c|c|c|c|}
\hline $\begin{array}{l}\text { Tipo de muestra/ } \\
\text { subproductos } \\
\text { encontrados }\end{array}$ & $\begin{array}{l}\text { Cloroformo } \\
(\mu g / L) \\
\text { (máx. permitido } \\
200 \mu g / L)\end{array}$ & $\begin{array}{l}\text { Bromodiclorometano } \\
(\mu g / L) \\
\text { (máx. permitido } 60 \mu g / L)\end{array}$ & $\begin{array}{l}\text { Dibromoclorometano } \\
(\mu g / L) \\
\text { (máx. permitido } 100 \mu g / L)\end{array}$ & $\begin{array}{c}\text { Tribromometano } \\
(\mu g / L) \\
\text { (máx. permitido } 100 \mu g / L)\end{array}$ \\
\hline $\begin{array}{l}\text { Agua naciente } \\
\text { (I muestra) }\end{array}$ & NS & $\begin{array}{l}\text { I muestra } \\
\text { valor máximo de: } \\
264,7\end{array}$ & NS & NS \\
\hline $\begin{array}{l}\text { Agua Planta } \\
\text { Tratamiento } \\
\text { (5 muestras) }\end{array}$ & $\begin{array}{l}4 \text { muestras } \\
\text { valor máximo de: } \\
505,1\end{array}$ & NS & $\begin{array}{l}3 \text { muestras } \\
\text { valor máximo de: } \\
|57,|\end{array}$ & $\begin{array}{c}5 \text { muestras } \\
\text { valor máximo de } \\
298,3\end{array}$ \\
\hline
\end{tabular}

*NS: No se encontraron muestras superando el máximo admisible. 
riñón y el hígado por ingestión, dando lugar a alteraciones funcionales y es posiblemente carcinógeno para los seres humanos (ATSDR, 2005).

Estudios en animales indican que la exposición prolongada al bromoformo o al dibromoclorometano puede producir cáncer del hígado y riñones. Aunque no se pueden atribuir definitivamente casos de cáncer en seres humanos a la exposición a estas sustancias, esto es materia de preocupación especial, ya que mucha gente está expuesta a bajos niveles de bromoformo y dibromoclorometano en el agua potable clorada (ATSDR, 2005).

La probabilidad de ingerir bromoformo o dibromoclorometano en el agua varía con la temporada, la temperatura del agua, la presencia de otras sustancias químicas en el agua, el método de desinfección y otros factores. No obstante, si hay evidencia de contaminación patógena (tales como bacterias, virus, etc.), los riesgos a la salud asociados con el consumo de agua no desinfectada son mucho más altos que el riesgo de exposición al bromoformo o al dibromoclorometano (ATSDR, 2005).

Hay métodos para tratar el agua que la gente usa en sus hogares que podrían reducir la exposición al bromoformo y el dibromoclorometano a través del agua potable clorada. Estos incluyen simples procedimientos como, por ejemplo, conectar filtros de carbón activado a los grifos para el agua.

La mayoría de estos subproductos solubles no duran mucho tiempo en el cuerpo, se estima un total de ocho horas, no obstante, se debe tener verdadero cuidado en la ingesta de agua que se sienta con cargas altas de cloro residual, especialmente si provienen de sistemas de tratamiento de aguas superficiales.

El agua, para consumirla de forma segura, debe clorarse, no obstante, nuestro Reglamento de Calidad de Agua establece un máximo para entes operadores de acueductos de 0,6 mg/L. Todas las plantas de tratamiento de agua potable manejan niveles superiores a este y no es usual que aguas de naciente cloradas superen ese límite.

\section{Conclusiones y recomendaciones}

El método de cuantificación por cromatografía de gases con detector de masas mostró ser adecuado y robusto para la detección y cuantificación de trihalometanos.
Se encontró que la aparición de subproductos es intermitente en las aguas muestreadas en un punto específico de los sistemas de tratamiento completo, o sea de agua superficial, tanto en Cartago como en San José. Esto hace que medidas remediales como disminuir la concentración de cloro agregado, y por ende el de cloro residual, pueden tener un efecto positivo en el sentido de no superar los valores máximos permitidos de subproductos específicos más allá de lo establecido por el Reglamento de Calidad de Agua del país.

La diferencia entre la aparición de subproductos en cantidades que superan el máximo admisible en agua superficial y en agua subterránea es relevante, siendo en este sentido el consumo de agua de nacientes tratada bastante segura para la población según los resultados de esta investigación.

Como una medida adoptada por la Municipalidad del Cantón Central de Cartago, se disminuyó el cloro agregado en el punto final de su planta de tratamiento y se decidió evitar las precloraciones, por lo tanto están trabajando actualmente con residuales de $0,8 \mathrm{mg} / \mathrm{L}$, que son mucho menores que los valores anteriores de trabajo, de 1,2 mg/L.

Por el tipo de resultados obtenidos, no se encontró relación entre subproductos formados en aguas de nacientes cloradas y el tipo de suelo (pues todas las nacientes corresponden a suelos diferentes según resultados de investigaciones anteriores), aunado a la poca concentración en las zonas de estudio del carbono orgánico total en el agua muestreada.

Es recomendable valorar otro kit de estándares para otros subproductos más tóxicos e inestables que está disponible actualmente en el mercado internacional. Se trata del EPA 55IB Halogenated Volatiles Mix, que tiene estándares para los subproductos de Bromocloroacetonitrilo, Cloropicrina, Dibromoacetonitrilo, Tricloroacetonitrilo, I - I-Dicloro-2 propanona, I - I - -Tricloropropanona.

Para estudios posteriores, para abastecimientos de agua superficial se recomienda el seguimiento de los subproductos en altas concentraciones en agua almacenada.

Asimismo, hacer un seguimiento de la formación de subproductos en invierno, pues se sabe que el cloro agregado en esa época es mayor y la cantidad de carbono orgánico total puede aumentar, especialmente en sistemas de aguas superficiales. 
Este trabajo se considera relevante en el manejo del agua en Costa Rica por cuanto es la primera vez que se determinan este tipo de subproductos en las aguas y se contrastan tipos de agua superficial y subterránea.

Es importante dimensionar el problema y educar a la población costarricense, principalmente a los entes operadores de acueductos, incluido el Laboratorio Nacional de Acueductos y Alcantarillados, con respecto al riesgo de formación de subproductos: entre más cloro se agregue a las aguas dispensadas, mayor es el riesgo en su formación.

\section{Agradecimientos}

A la Vicerrectoria de Investigación y Extensión del Instituto Tecnológico de Costa Rica y a la Municipalidad del Cantón Central de Cartago, por el financiamiento de la investigación.

\section{Bibliografía}

Agencia de Protección Ambiental de Estados Unidos (EPA). (Mayo de 2000). Environmental Protection Agency EPA Recuperado el 30 de mayo de 2013 de http://waterepa. gov/drink/agua/losninos.cfm

Agencia para Sustancias Tóxicas y Registro de Enfermedades (ATSDR). (2005). Resumen de Salud Pública para Bromoformo y Dibromoclorometano, 2005.

Aggazzotti, G., Righi, E., Fantizzi, G., Biasotti, B. et al. (2004). Chlorination by-products (CBPs) in drinking water and adverse pregnancy outcomes in Italy. Journal of Water and Health 233-247.

Berdonces, J.L. (2008). La problemática del tratamiento del agua potable. Medicina Naturista 2(2): 69-75.

Calderón, J., Capell, C., Centrich, F., Artazcoz, L. et al. (2002). Subproductos halogenados de la cloración en el agua de consumo público. Gaceta Sanitaria. 16(3): 241-243.

Cloroformo. (2007). Documentación toxicológica profesional para el establecimiento del límite de exposición profesional. Instituto Nacional de Seguridad e Higiene en el Trabajo. DLEP 26.
Dodds, L., King, W., Allen, A., Armson, A., Fell, D. \& Nimrod, C. (2004). Trihalomethanes in Public Water Supplies and Risk of Stillbirth. Epidemiology 15(2): I79-।86.

Nieuwenhuijsen, M., Martínez, D., Grellier, J., Bennett, J. et al. (2009). Chlorination Disinfection By-Products in Drinking Water and Congenital Anomalies: Review an Meta-Analyses. Environmental Health Perspectives I| 7( I0): |486-| 493.

Nieuwenhuijsen, M., Smith, R., Golfinopoulos, S., Best, N., Bennett, J., Aggazzotti, G. et al. (2009). Health impacts of long-term exposure to disinfection by-products in drinking water in Europe: HIWATE. Journal of Water and Health 185-207.

Ochoa Barajas, H.A. (2004). Desinfectante y nuevas tecnologías utilizadas en el tratamiento del agua potable. Trabajo de investigación para optar por el título de especialista en Química Ambiental. (D.G. Ortíz, Ed.). Bucaramanga: Universidad Industrial de Santander, Facultad de Ciencias, Escuela de Química.

República de Costa Rica (03 de mayo de 2005). Reglamento de calidad del agua potable, No 32327-S. Diario Oficial La Gaceta Nº 84, págs. 80-60.

Ríos, D. (2004.). Riesgos biológicos y subproductos de la desinfección en el agua bebida. Tesis de Mestría: Magíster en Ingeniería Ambiental, Universidad Oriental del Uruguay, Facultad de Ingeniería, Uruguay. Fuente original: Xie F. Yuefeng. Disinfection By-Products in Drinking Water. Formation, Analysis and Control. Lewis Publishers, I54 pp.

Sánchez Zafra, A. (2008). Efectos de los trihalometanos sobre la salud. Higiene y Salud Ambiental (8): 280-290.

Sánchez, L.D., Rodríguez, S., Escobar, J.C. \& Torres, P. (20l0). Modelación del cloro residual y subproductos de la desinfección en un sector piloto del sistema de distribución de agua potable de la ciudad de Cali. Ingeniería y Competitividad 12(I): 127-138.

Villanueva, C., Cantor, K., Cordier, S., Jaakkola, J., King, W., Lynch, C. et al. (2004). Disinfection By-products and Bladder Cancer: A pooled Analysis. Epidemiology 15, 357-367.

Villanueva, C., Cantor, K., Grimalt, J., Malats, N., Silverman, D., Tardon, A. et al (2007). Bladder Cancer and Exposure to Water Disinfection By-Products through Ingestion, Bathing, Showering and Swimming in Pools. American Journal of Epidemiology 165(2): I48-156.

Vuolo, J., Domenech, A., Friedrichs, M., Siroti, D., Casamayore, M., Temporale, R. et al. (s.f.). (O.P. [PAHO], Ed.). Recuperado el 15 de mayo de 2013 de http://www.bvsde.paho.org/ bvsaidis/argentina | 4/vuolo.pdf 